\title{
BRPKM
}

Buletin Riset Psikologi dan Kesehatan Mental

http://e-journal.unair.ac.id/index.php/BRPKM

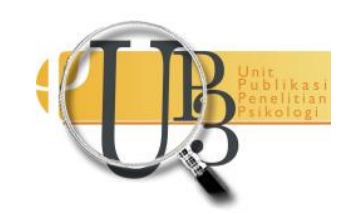

ARTIKEL PENELITIAN

\section{Hubungan antara Dukungan Sosial dengan Self Compassion Pada Remaja dengan Orang Tua Bercerai}

\author{
REVI CANIA IRNANDA \& HAMIDAH*
}

Departemen Psikologi Klinis dan Kesehatan Mental, Fakultas Psikologi Universitas Airlangga

\begin{abstract}
ABSTRAK
Penelitian ini bertujuan untuk mengetahui hubungan antara dukungan sosial dengan self compassion pada remaja dengan orang tua bercerai. Kriteria partisipan pada sampel yaitu berusia 13-18 tahun yang memiliki orang tua bercerai. Alat ukur yang digunakan untuk skala dukungan sosial yaitu Multidimensional Scale of Perceived Social Support (MSPSS) dan alat ukur untuk mengukur self compassion menggunakan Skala Welas Diri (SWD). Penelitian ini menggunakan analisis data uji korelasi Spearman's Rho. Hasil uji korelasi menunjukkan nilai signifikansi sebesar 0.000 dan memiliki arah positif yang artinya terdapat hubungan signifikan yang searah antara dukungan sosial dengan self compassion pada remaja dengan orang tua bercerai sehingga jika dukungan sosial meningkat maka self compassion juga meningkat.
\end{abstract}

Kata kunci: dukungan sosial, remaja dengan orang tua bercerai, self compassion

\section{ABSTRACT}

The aim of this study is to discover the relationship between social support and self compassion in adolescents with divorced parents. The criteria for the subjects in the sample were 13-18 years old who had divorced parents. The instrument that was used to measure the social support is Multidimensional Scale of Perceived Social Support (MSPSS) and to measure the self compassion is Skala Welas Diri (SWD). This research use Spearman's Rho correlation test data analysis. The results of the correlation test show a significance value of 0.000 and have a positive direction, which means that there is a significant positive relationship between social support and self-compassion for adolescents with divorced parents so that if social support increases, self-compassion also increases.

Keywords: adolescents with divorced parents, self compassion, social support

Buletin Penelitian Psikologi dan Kesehatan Mental (BRPKM), 2021, Vol. 1(1), 396-405

*Alamat korespondensi: Fakultas Psikologi Universitas Airlangga, Kampus B Universitas Airlangga Jalan Airlangga 4-6 Surabaya 60286. Surel: hamidah@psikologi.unair.ac.id

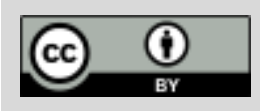

Naskah ini merupakan naskah dengan akses terbuka dibawah ketentuan the Creative Common Attribution License (CC-BY-4.0) (http://creativecommons.org/licenses/by/4.0), sehingga penggunaan, distribusi, reproduksi dalam media apapun atas artikel ini tidak dibatasi, selama sumber aslinya disitir dengan baik. 


\section{PEN D A H U L U A N}

Semua manusia menginginkan kebahagiaan, salah satunya yaitu memiliki keluarga yang harmonis. Namun, tidak semua orang dapat memiliki keluarga harmonis karena banyaknya permasalah keluarga yang salah satunya yaitu perceraian orang tua. Menurut data dari Badan Pusat Statistik (BPS), perceraian di Indonesia terus mengalami peningkatan selama tahun 2015 hingga 2019. Pada tahun 2015 yaitu terdapat 347.256 kasus dan terjadi peningkatan terus menerus hingga mencapai 439.002 kasus pada tahun 2019 (Badan Pusat Statistik Indonesia, 2020).

Saat ini perceraian menjadi hal yang wajar sebagai bagian dari kehidupan pernikahan meskipun hal tersebut tidak menguntungkan bagi keluarga dan anak-anak mereka (Tahirović \& Demir, 2018). Banyaknya pasangan yang bercerai akan memiliki dampak secara langsung pada mereka yang telah memiliki anak khususnya pada remaja. Masa remaja adalah masa yang penuh gejolak dan seringkali merasakan perubahan suasana hati atau disebut seperti "storm and stress" (Santrock, 2011). Masa remaja merupakan tahap perkembangan yang juga menekankan pada perkembangan fisik yang pesat, pencarian jati diri dan memposisikan diri mereka pada tahap pendewasaan. Tahapan ini ditandai dengan perubahan jati diri, cara berpikir, tanggung jawab dan kemandirian. Oleh sebab itu sebagian besar masa remaja ditandai dengan pergolakan serta berbagai macam ketakutan akan kegagalan yang dialami (Tahirović \& Demir, 2018).

Menurut Tahirović dan Demir (2018), remaja yang menghadapi masalah perceraian orang tua seringkali menunjukkan beberapa bentuk reaksi emosional yang ditandai dengan rasa sakit seperti kemarahan, kondisi dan perasaan kehilangan serta perasaan tidak percaya atas perceraian yang telah terjadi. Hal tersebut dikarenakan remaja masih membutuhkan kasih sayang dan rasa aman dalam keluarga, namun dalam banyak kasus perceraian yang seringkali disebabkan oleh konflik yang terus terjadi dapat mengubah suasana keluarga menjadi tegang dan tidak aman. Penilaian remaja tentang ketidakamanan keluarga tersebut dapat menyebabkan perkembangan gejala kecemasan pada remaja (Tahirović \& Demir, 2018). Berdasarkan penelitian Pálmarsdóttir (2015) tentang efek dari perceraian orang tua dengan sampel remaja sekolah menengah bahwa, perceraian orang tua dapat mengakibatkan kecemasan dan depresi pada remaja. Remaja yang telah melalui perceraian orang tua secara signifikan menunjukkan adanya tingkat kecemasan yang lebih tinggi (Pálmarsdóttir, 2015).

Perceraian orang tua memiliki dampak jangka panjang maupun jangka pendek bagi remaja. Banyak remaja dengan orang tua bercerai melaporkan bahwa mereka memiliki kepuasan hidup yang lebih rendah dan merasa tidak aman dengan lingkungannya sendiri dibandingkan dengan teman-teman mereka yang keluarganya masih utuh (Pálmarsdóttir, 2015). Hetherington (2003, dalam Strong et al., 2011) melaporkan bahwa $20 \%$ sampel remaja dengan orang tua yang bercerai memiliki beberapa permasalahan termasuk depresi, perilaku antisosial yang tidak bertanggung jawab dan memiliki angka putus sekolah yang tinggi. Berdasarkan penelitian-penelitian yang telah dijelaskan dapat disimpulkan bahwa dampak yang paling sering muncul pada remaja saat menghadapi perceraian orang tua adalah kecemasan dan depresi.

Tahirović \& Demir (2018) menyebutkan bahwa salah satu penyebab munculnya gejala kecemasan dan depresi pada remaja dengan orang tua bercerai karena mereka merasa bersalah terhadap perceraian orang tuanya. Remaja seringkali menilai bahwa perceraian orang tua adalah akhir dari kehidupan keluarga, ketidakpastian pada masa depan dan hilangnya kasih sayang dari salah satu orang tua yang menyebabkan munculnya masalah psikologis pada remaja (Tahirović \& Demir, 2018). Berdasarkan penjelasan di atas dapat disimpulkan bahwa perceraian orang tua dapat memunculkan rasa bersalah, kehilangan, serta perasaan tidak aman pada remaja sehingga menilai bahwa perceraian merupakan

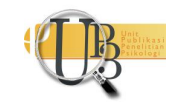


akhir dari kehidupan keluarga, hilangnya sosok salah satu orang tua, serta ketidakpastian akan masa depan yang dapat meningkatkan tingkat kecemasan dan depresi pada remaja. Wilson (2017) menyebutkan bahwa gangguan kecemasan dan depresi pada remaja dapat diatasi dengan self compassion. Penelitian Bluth \& Blanton (2015, dalam Wilson, 2017) menunjukkan bahwa remaja yang memiliki self compassion akan memiliki gejala yang lebih rendah pada depresi dan kecemasan.

Self compassion adalah tentang terbuka dan menerima diri sendiri secara penuh serta berusaha untuk meringankan penderitaan saat berada dalam keadaan yang sulit dan menyakitkan. Self compassion terdiri dari tiga komponen utama yaitu, self kindness, common humanity dan mindfulness (Neff, 2003). Penelitian Bluth, Mullarkey, \& Lathren (2018, dalam Bluth, 2018) mengenai self compassion melaporkan bahwa remaja dengan Self compassion yang tinggi memiliki kemungkinan lebih kecil untuk mengalami depresi, kecemasan, stres serta merasakan perasaan malu atau takut akan kegagalan pada diri. Selain itu self compassion dapat menjadi pelindung terhadap kerentanan seperti perasaan terisolasi, ketidakstabilan suasana hati yaitu kecemasan dan depresi (Bluth, 2018). Ditemukan bahwa self compassion berkaitan dengan meningkatnya inisiatif diri, kebahagiaan, optimisme, eksplorasi dan pengaruh positif (Neff \& Vonk, 2009). Self compassion juga dapat dijadikan sebagai pelindung diri dari perbandingan sosial, perasaan marah dan pemikiran yang tertutup (Neff \& McGehee, 2010).

Berdasarkan hasil penelitian yang telah dijelaskan, dapat disimpulkan bahwa self compassion sangat penting bagi remaja dalam menghadapi perceraian orang tua. Perceraian orang tua yang menghadapkan remaja pada situasi hilangnya salah satu orang tua dan putusnya komunikasi antara orang tua dan anak membuat mereka merasa berduka (Çağlar \& Taş, 2018). Selain itu remaja juga merasa bersalah terhadap perceraian orang tua serta menganggap bahwa perceraian merupakan akhir dari kehidupan keluarga, ketidakpastian pada masa depan dan hilangnya kasih sayang dari salah satu orang tua sehingga dapat menyebabkan munculnya gejala kecemasan dan depresi pada remaja (Tahirović \& Demir, 2018). Hal tersebut dapat diatasi dengan adanya self compassion karena self compassion sangat berkaitan dengan kesejahteraan psikologis seperti peningkatan kebahagiaan, optimisme, penurunan kecemasan dan depresi sehingga dapat membantu remaja dalam menghadapi pengalaman yang sulit khususnya perceraian orang tua.

Faktor-faktor yang dapat mempengaruhi self compassion adalah jenis kelamin, usia, lingkungan dan budaya. Menurut Neff (2003) perempuan memiliki self compassion yang lebih rendah dari laki-laki. Usia remaja memiliki tingkat self compassion yang rendah daripada kelompok usia lain karena remaja seringkali mengevaluasi diri secara negatif. Pada faktor budaya, orang Asia memiliki tingkat self compassion yang tinggi dibandingkan dengan orang-orang Barat (Neff, 2003). Pada faktor lingkungan dijelaskan bahwa peran keluarga merupakan salah satu hal yang penting bagi remaja agar memiliki self compassion yang tinggi. Menurut Neff \& McGehee (2010) remaja akan memiliki tingkat self compassion yang tinggi apabila dibesarkan dari keluarga suportif dan fungsional. Oleh sebab itu, dapat disimpulkan bahwa self compassion dapat dikembangkan oleh beberapa faktor salah satunya yaitu lingkungan. Faktor lingkungan memiliki pengaruh terhadap tingginya tingkat self compassion pada remaja. Salah satu bentuk faktor lingkungan yang mempengaruhi tingkat self compassion pada remaja adalah dengan adanya dukungan sosial.

Dukungan sosial yaitu hubungan transaksi antar individu dimana sifat dari bentuk transaksi dapat ditentukan dengan banyak cara. Definisi lain dari dukungan sosial yaitu suatu kelompok atau individu yang memberikan kenyamanan, kepedulian, penghargaan atau bantuan yang tersedia untuk orang lain. Menurut Shumaker dan Brownell (1984, dalam Zimet et al., 1998) mencirikan bahwa dukungan sosial merupakan pertukaran sumber daya antara dua individu yang dianggap sebagai penyedia atau penerima dimana bertujuan untuk meningkatkan kesejahteraan pada penerima. Dukungan sosial dapat 
berasal dari berbagai sumber misalnya, pasangan, keluarga, teman atau organisasi komunitas (Sarafino, 2011).

Salah satu sumber dukungan sosial yaitu keluarga. Keluarga seringkali dianggap sebagai tempat paling aman dalam memberikan kenyamanan serta tempat perlindungan dan kebutuhan bagi anak khususnya remaja. Kurangnya dukungan, sikap pengabaian dan merendahkan serta perilaku buruk lainnya yang dilakukan orang tua pada remaja seringkali membuat remaja mengalami tekanan atau stres yang menghalangi perkembangan perasaan dan keyakinan diri remaja (Mulyana \& Purnamasari, 2010). Sebagian besar penelitian tentang jaringan sosial remaja akan berfokus pada keluarga dan hubungan dengan teman. Hubungan dengan keluarga maupun teman memiliki pengaruh yang besar bagi perkembangan remaja (Hombrados-Mendieta et al., 2012).

Terdapat penelitian empiris yang secara konsisten menunjukkan bahwa dukungan sosial merupakan prediktor penting dari kesejahteraan psikologis pada remaja (Hombrados-Mendieta et al., 2012). Menurut Burnett \& Demnar (1996, dalam Salazar, 2015) kedekatan yang dirasakan suatu individu dengan teman-temannya dapat mendorong individu tersebut untuk mengekspresikan kasih sayang pada diri sendiri yang sekaligus dapat meningkatkan kualitas hubungan dengan teman. Selain itu jika orang lain memberikan dukungan secara penuh pada suatu individu, maka individu itu akan dapat menyayangi dan lebih baik pada dirinya sendiri (Neff \& McGehee, 2010). Hal ini dapat disimpulkan bahwa remaja membutuhkan dukungan sosial dari orang-orang terdekat khususnya seperti keluarga dan teman atau significant others untuk dapat meningkatkan self compassion pada diri remaja.

Menurut hasil penelitian Nafisah, Hendriyani \& Martiarin (2018) mengenai hubungan dukungan keluarga dengan self compassion pada sampel remaja di panti asuhan bahwa terdapat hubungan secara positif antara dukungan keluarga dengan self compassion. Semakin tinggi dukungan keluarga pada remaja tersebut maka semakin tinggi pula tingkat self compassion pada mereka. Studi Maheux dan Price (2016) mengenai hubungan dukungan sosial dan PTSD melalui self compassion menunjukkan bahwa dukungan sosial dapat mengurangi gejala depresi, PTSD, dan GAD dengan adanya peningkatan self compassion, selain itu penelitian ini juga menunjukkan bahwa seseorang yang mengalami dampak negatif akibat penderitaan yang dialami akan terlindungi dengan adanya dukungan sosial dan self compassion yang saling berkaitan. Hasil penelitian Wilson, dkk (2019) menunjukkan bahwa dukungan sosial memiliki hubungan yang signifikan dengan self compassion, mindfulness dan hasil dari kesejahteraan psikologis yang positif seperti kesejahteraan psikologis dan subjective happiness serta memiliki tingkat yang lebih rendah dari depresi dan stres.

Berdasarkan penjelasan di atas, dapat disimpulkan bahwa remaja membutuhkan adanya dukungan dari orang terdekatnya sehingga dapat meningkatkan self compassion agar dapat bertahan dalam menghadapi perceraian orang tua dan terhindar dari dampak negatif. Hal tersebut dikarenakan tingkat self compassion pada remaja akan tinggi apabila bersamaan dengan adanya dukungan dari keluarga dan lingkungan sekitar (Neff \& McGehee, 2010). Namun hingga saat ini masih kurang penelitian mengenai dukungan sosial dan self compassion khususnya pada remaja dengan orang tua yang bercerai. Oleh sebab itu peneliti ingin mengetahui hubungan antara dukungan sosial dan self compassion pada remaja dengan orang tua bercerai. 


\section{Desain Penelitian}

\section{E T O D E}

Penelitian ini menggunakan pendekatan kuantitatif eksplanatori yang bertujuan untuk menguji dan mendapatkan informasi mengenai hubungan antara dukungan sosial (variabel $\mathrm{x}$ ) dengan self compassion (variabel y) pada remaja dengan orang tua bercerai. Teknik pengambilan sampel pada penelitian ini yaitu menggunakan teknik nonprobability sampling dengan purposive sampling. Teknik pengumpulan data menggunakan teknik survei dalam bentuk kuesioner.

\section{Partisipan Penelitian}

Partisipan pada penelitian ini yaitu remaja berusia 13 sampai 18 tahun, terdiri dari perempuan atau laki-laki yang memiliki orang tua yang telah bercerai. Partisipan penelitian ini yaitu sebanyak 643 orang dengan tingkat pendidikan yang terdiri dari SMP, SMA, SMK, Kuliah dan tidak sekolah. Sebelum partisipan mengisi kuesioner penelitian, partisipan diberikan informed consent pada halaman depan kuesioner penelitian secara online di google form. Informed consent tersebut wajib dibaca dan disetujui sebelum mengisi kuesioner penelitian ini. Pada penelitian ini terdapat 643 partisipan dengan $M_{\text {usia }}=15,5 ; S D_{\text {usia }}=1,87 ; 90,4$ persen perempuan dan 9,6 persen laki-laki.

\section{Pengukuran}

Skala yang akan digunakan pada penelitian ini yaitu skala dukungan sosial dan skala self compassion. Untuk mengukur dukungan sosial yaitu menggunakan skala MSPSS milik Zimet (1988), penggunaan skala ini diadaptasi dan diterjemahkan dalam bahasa Indonesia oleh Hakim (2019) berdasarkan alat ukur MSPSS milik Zimet (1988) yang mengukur tentang perceived social support berdasarkan tiga sumber dukungan sosial. Sumber dukungan sosial tersebut yaitu pada orang tua, teman sebaya dan significant other. Skala MSPSS terdiri dari 12 aitem dan menggunakan skala likert untuk merespon tiap aitemnya. Pada skala ini akan menggunakan tujuh respon yaitu skala 1 untuk respon "sangat tidak setuju" dan skala 7 untuk "sangat setuju" (Zimet et al., 1998).

Untuk mengukur self compassion yaitu menggunakan skala Self Compassion yang diterjemahkan dalam Bahasa Indonesia oleh Sugianto, dkk (2020) berdasarkan alat ukur milik Neff (2003) dan diberi nama SWD (Skala Welas Diri). Pada skala welas diri terdiri dari 26 aitem dan menggunakan skala likert dalam merespon tiap aitem. Skala ini akan menggunakan lima respon yaitu skala 1 untuk respon "hampir tidak pernah" dan skala 5 untuk "hampir selalu".

Validitas penelitian ini didapatkan dari penilaian Professional Judgement yang dilakukan oleh Dosen Fakultas Psikologi Universitas Airlangga, selain itu juga dengan membandingkan nilai sig. (2-tailed) dengan probabilitas 0.05 . Hasil uji validitas pada penelitian ini untuk keseluruhan aitem skala dukungan sosial dan skala welas diri (SWD) yaitu bernilai 0.000 dan Pearson Correlation bernilai positif sehingga dapat dikatakan keseluruhan aitem alat ukur valid.

Penelitian ini melakukan uji asumsi yang terdiri dari uji normalitas dan uji linearitas, kemudian melakukan uji korelasi. Uji normalitas dengan menggunakan teknik Kolmogorov-Smirnov untuk mengetahui data berdistribusi normal atau tidak. Penelitian ini memiliki data yang tidak berdistribusi normal sehingga menggunakan teknik korelasi non-parametrik Spearman's Rho. 


\section{Reliabilitas alat ukur}

Berdasarkan hasil uji cronbach's alpha pada alat ukur MSPSS yang digunakan untuk mengukur dukungan sosial memiliki nilai reliabilitas yang tinggi yaitu $\alpha=.884$, kemudian untuk hasil pada alat ukur welas diri (SWD) yang digunakan untuk mengukur self compassion yaitu memiliki nilai reliabilitas yang tinggi sebesar $\alpha=.839$

\section{Analisis Data}

Teknik analisis data yang digunakan yaitu uji analisis teknik korelasi spearman's rho dengan menggunakan bantuan dari program SPSS 22.0 for windows.

\section{HAS I L P E N E L I T I A N}

Partisipan pada penelitian ini terdiri dari 643 orang. Partisipan dikelompokkan berdasarkan karakteristik sosiodemografis yaitu, usia, jenis kelamin, pendidikan saat ini dan tempat tinggal atau asal partisipan. Diketahui bahwa usia partisipan pada penelitian ini terdiri dari usia 13 hingga 18 tahun, dan didominasi oleh kelompok usia 18 tahun yaitu sebanyak 187 orang atau 29\%, kemudian pada usia 17 tahun yaitu sebanyak 153 orang atau 24\%. Selanjutnya untuk usia 16 tahun sebanyak 115 orang atau 18\%. Partisipan usia 15 tahun sebanyak 102 orang atau 16\%, kemudian untuk usia 14 tahun sebanyak 60 orang atau $9 \%$ dan yang paling sedikit yaitu pada kelompok usia 13 tahun sebanyak 26 orang atau 4\%. Berdasarkan kelompok jenis kelamin, lebih didominasi pada jenis kelamin perempuan yaitu sebanyak 581 orang atau 90\% sedangkan laki-laki hanya 62 orang atau 10\%. Pada kelompok pendidikan saat ini, didominasi pada kelompok SMA yaitu sebanyak 249 orang atau 39\% dan untuk terbanyak kedua yaitu SMK sebanyak 212 orang atau 33\%.

Kemudian untuk persebaran daerah asal partisipan cukup beragam dan mayoritas partisipan penelitian ini berasal dari Jawa Timur yaitu sebanyak 127 orang atau 19,75\%, kemudian kedua yaitu Jawa Barat sebanyak 122 orang atau 18,97\%, ketiga yaitu Jawa tengah sebanyak 96 orang atau 14,93\%, kemudian Jakarta sebanyak 48 orang atau 7,47\%, Banten sebanyak 41 orang atau 6,38\%, Sumatera Utara sebanyak 27 orang atau 4,20\%, Sumatera Selatan sebanyak 25 orang atau 3,89\%, DIY sebanyak 20 orang atau 3,11\%, Kepulauan Riau sebanyak 18 orang atau 2,80\%, Sulawesi Selatan sebanyak 17 orang atau 2,64\%, Kalimantan Timur sebanyak 14 orang atau 2,18\%, Sumatera Barat sebanyak 13 orang atau 2,02\%, Lampung dan Kalimantan Selatan sebanyak 12 orang atau 1,87\%, Sulawesi Utara sebanyak 10 orang atau 1,56\%, Aceh sebanyak sembilan orang atau 1,40\%, Bali sebanyak enam orang atau 0,93\%, Kalimantan Timur sebanyak lima orang atau 0,78\%, Kalimantan Tengah sebanyak empat orang atau 0,62\%, Nusa Tenggara Barat sebanyak tiga orang atau 0,47\%, Nusa Tenggara Timur dan Papua sebanyak dua orang atau $0,31 \%$, kemudian yang paling sedikit dan hanya satu orang atau 0,16\% yaitu Bengkuli, Jambi, Kalimantan Utara, Bangka Belitung, Maluku dan Maluku utara serta Sulawesi Tenggara.

\section{Uji Asumsi}

Pada penelitian ini, peneliti melakukan uji asumsi yaitu uji normalitas yang menggunakan teknik Kolmogorov-Smirnov dan uji linearitas dengan teknik compare means. Pada variabel dukungan sosial memiliki nilai signifikansi $\mathrm{p}=0.017$ atau $\mathrm{p}<0.05$ dan variabel self compassion memiliki nilai signifikansi $\mathrm{p}=0.000$ atau $\mathrm{p}<0.05$. Sehingga dapat disimpulkan bahwa data tidak berdistribusi normal. Kemudian pada uji linearitas diketahui bahwa taraf signifikansi linearitas pada variabel penelitian ini bernilai $\mathrm{p}=0.616$ atau $\mathrm{p}>0.05$. Hal ini dapat disimpulkan bahwa hubungan pada variabel tidak linear.

Uji Korelasi 
Uji korelasi pada penelitian ini menggunakan teknik korelasi non-parametrik Spearman's Rho. Nilai koefisien korelasi yaitu $(\mathrm{r}(643)=0.231, \mathrm{p}=0.000$ ) yang artinya bahwa terdapat hubungan yang signifikan antara dua variabel dan kedua variabel memiliki hubungan yang lemah. Pada nilai koefisien korelasi menunjukkan nilai positif yang artinya memiliki hubungan searah sehingga dapat dikatakan bahwa jika variabel dukungan sosial mengalami peningkatan maka variabel self compassion juga mengalami peningkatan. Dapat disimpulkan bahwa hipotesis pada penelitian diterima.

Analisis Tambahan

Peneliti melakukan analisis tambahan dengan menggunakan uji Mann-Whitney dan Kruskal Wallis. Pada uji Mann-Whitney bertujuan untuk mengetahui perbedaan antara dua independen kelompok pada suatu variabel. Pada uji Kruskal Wallis memungkinkan untuk membandingkan skor pada suatu variabel untuk tiga atau lebih kelompok.

Hasil uji Mann-Whitney menunjukkan bahwa pada variabel self compassion, nilai mean pada laki-laki 395.35 dan pada perempuan 314.17 dan nilai $\mathrm{p}=0,001$. Hal tersebut dapat diartikan bahwa nilai mean laki-laki lebih tinggi daripada perempuan dan terdapat perbedaan yang signifikan antara kelompok lakilaki dan perempuan pada variabel self compassion.

Untuk hasil uji Kruskal Wallis menunjukkan bahwa mean pada usia 13-15 tahun memiliki nilai yang rendah daripada usia 16-18 tahun. Diketahui bahwa nilai sig. atau $\mathrm{p}=0,708$. Nilai $\mathrm{p}>$ dari 0,05 yang artinya tidak terdapat perbedaan yang signifikan antar kelompok usia dari 13-18 tahun pada variabel self compassion.

\section{I S K U S I}

Berdasarkan hasil uji korelasi menunjukkan bahwa nilai signifikansi sebesar 0.000 dan $\rho=0.23$ dapat dikatakan bahwa terdapat hubungan yang signifikan antara dukungan sosial dan self compassion dan memiliki hubungan yang positif. Hubungan positif diartikan bahwa terdapat hubungan yang searah yang mana apabila dukungan sosial mengalami peningkatan maka self compassion juga mengalami peningkatan dan begitu pula sebaliknya jika dukungan sosial menurun maka self compassion juga akan menurun. Disimpulkan bahwa hipotesis yang diajukan pada penelitian ini diterima. Temuan pada penelitian ini selaras dan didukung dengan penelitian sebelumnya yang dilakukan bahwa terdapat hubungan yang signifikan antara dukungan sosial dan self compassion (Wilson et al., 2019). Menurut Maheux dan Price (2016) bahwa terdapat hubungan positif antara dukungan sosial dan self compassion.

Dukungan sosial dapat berasal dari berbagai sumber, menurut teori ekologis Bronfenbrenner (2005) bahwa keluarga inti dan teman sebaya merupakan sumber dukungan sosial yang relevan (HombradosMendieta et al., 2012). Selain itu dukungan sosial juga didapatkan dari pasangan romantis, hewan peliharaan, rekan kerja atau ikatan komunitas. Menurut Salazar (2015) teman memiliki peran sebagai penyangga untuk membantu individu mengatasi kejadian yang sulit, dan hal tersebut tergantung pada cara individu mempersepsikan dukungan sosialnya yang juga berkaitan dengan self compassion. Hal tersebut selaras dengan penelitian yang dilakukan oleh Burnett \& Demnar (1996, dalam Salazar, 2015) bahwa individu yang merasakan kedekatan dengan teman-temannya dapat membuat individu tersebut mudah untuk mengekspresikan kasih sayang pada dirinya sendiri.

Menurut Neff (2003) faktor lingkungan memiliki peran penting bagi remaja agar memiliki self compassion yang tinggi, salah satunya yaitu peran keluarga. Menurut Neff \& McGehee (2010) remaja akan memiliki tingkat self compassion yang tinggi apabila dibesarkan dari keluarga suportif dan fungsional. Hal ini selaras dengan penelitian milik Nafisah, Hendriyani \& Martiarin (2018) yang 
menunjukkan bahwa semakin tinggi dukungan keluarga yang didapatkan individu maka semakin tinggi pula tingkat self compassion pada diri.

Menurut Neff (2003) faktor-faktor yang mempengaruhi self compassion adalah jenis kelamin, usia, lingkungan dan budaya. Berdasarkan hasil analisis tambahan pada penelitian ini, ditemukan bahwa nilai mean pada jenis kelamin laki-laki lebih tinggi daripada perempuan dan memiliki nilai signifikansi $\mathrm{p}=$ 0.001 yang artinya mean variabel self compassion pada kelompok jenis kelamin laki-laki memiliki nilai yang lebih tinggi daripada perempuan. Hal tersebut selaras dan dibuktikan oleh penelitian Leadbeater \& Nolen-Hoksema, dkk (1999) bahwa perempuan lebih sering mengkritik diri sendiri dan sering melakukan perenungan diri sebagai bentuk coping daripada laki-laki sehingga perempuan dianggap memiliki tingkat self compassion yang rendah daripada laki-laki (Neff, 2003). Penyebab dari laki-laki memiliki self compassion yang tinggi karena mereka cenderung bisa menahan perasaan atas penderitaannya dengan kehangatan dan memiliki kesadaran penuh daripada perempuan, sebaliknya perempuan cenderung lebih kritis pada diri sendiri sehingga sering merasa terisolasi (Cunha et al., 2016).

Berdasarkan analisis tambahan mengenai kelompok usia partisipan, ditemukan bahwa nilai $\mathrm{p}=0.708$ atau $\mathrm{p}>$ dari 0.05 yang artinya tidak terdapat perbedaan yang signifikan pada variabel self compassion antar kelompok usia dari 13-18 tahun. Hasil tersebut sejalan dengan penelitian Neff \& McGehee (2010) yang menunjukkan bahwa tidak ditemukan perbedaan tingkat self compassion pada usia sekolah menengah dan mahasiswa. Menurut Neff (2003) pada usia remaja menunjukkan bahwa remaja memiliki tingkat self compassion yang rendah daripada kelompok usia lain karena remaja sering mengevaluasi diri secara negatif. Hal tersebut dapat berkaitan juga dengan ciri-ciri remaja menurut Hurlock (2002) bahwa masa remaja disebut sebagai masa yang tidak realistik karena remaja seringkali memandang diri berdasarkan keinginannya sendiri, apabila keinginan tersebut tidak sesuai dengan tujuan yang ingin dicapai maka akan menyebabkan mereka merasa emosi, marah dan kecewa.

\section{S I M P U L A N}

Berdasarkan hasil pada penelitian ini, dapat diketahui bahwa terdapat hubungan antara dukungan sosial dan self compassion pada remaja dengan orang tua bercerai. Hubungan tersebut bernilai positif yang artinya bahwa ada hubungan yang searah pada variabel, hal ini menunjukkan apabila dukungan sosial mengalami peningkatan maka self compassion juga mengalami peningkatan dan begitu pula sebaliknya jika dukungan sosial menurun maka self compassion juga akan menurun. Hipotesis yang diajukan pada penelitian ini diterima yaitu adanya hubungan antara dukungan sosial dan self compassion pada remaja dengan orang tua bercerai.

Saran bagi peneliti selanjutnya yang ingin melakukan penelitian serupa dapat mengkaji terkait pengaruh mengenai kedua variabel serta menambahkan kriteria yang lebih spesifik seperti lama waktu perceraian orang tua agar memperoleh data secara mendalam. Selain itu dapat menambahkan pertanyaan tambahan pada skala dukungan sosial untuk melengkapi komponen significant others seperti siapa orang terdekat partisipan selain keluarga dan teman.

Partisipan diharapkan dapat menjalin dan meningkatkan kualitas hubungan dengan orang tua dan orang disekitar seperti teman sebaya serta significant other. Hal tersebut diharapkan dapat mendorong partisipan untuk mengekspresikan kasih sayang pada diri sendiri atau self compassion sehingga dapat bertahan pada kondisi perceraian orang tua. Selain itu orang tua juga diharapkan dapat memberi dukungan secara penuh serta menjadi tempat perlindungan dan memberi kenyamanan bagi partisipan.

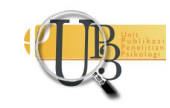


Teman dan significant others sekitar partisipan diharapkan memberikan kepedulian dan menjalin hubungan yang berkualitas dengan partisipan. Selain itu dapat memberi dukungan dan menjadi pendengar yang baik bagi partisipan, sehingga dengan adanya dukungan dan kepedulian secara penuh dari ketiga sumber diharapkan partisipan dapat bertahan pada kondisi perceraian orang tua.

\section{U C A P A N T ERIMAKASIH}

Penulis mengucapkan terima kasih kepada dosen pengajar, seluruh pihak Fakultas Psikologi Universitas Airlangga, dan teman-teman kuliah yang telah membantu dan mendukung dalam proses penelitian. Juga semua pihak serta partisipan yang meluangkan waktunya dalam membantu proses pengambilan data.

\section{DEKLARASI POTENSI TERJADINYAKONFLIKKEPENTINGAN}

Revi Cania Irnanda dan Hamidah tidak bekerja, menjadi konsultan, memiliki saham, atau menerima dana dari perusahaan atau organisasi manapun yang mungkin akan mengambil untung dari diterbitkannya naskah ini.

\section{PUSTAKA ACUAN}

Badan Pusat Statistik Indonesia. (2020). Statistik Indonesia 2020. BPS-Statistik Indonesia.

Bluth, K. (2018). Self-Compassion: A Potential Path to Adolescent Resilience and Positive Exploration. Journal of Child and Family Studies, 27, 3037-3047. https://doi.org/10.1007/s10826-018-11251

Çağlar, A., \& Taş, B. (2018). The Analysis of the Relationship between Bereavement Degrees of Adolescents Who have Lost Their Parents and Their Self-Compassion. Research on Education and Psychology (REP), 2(2), 144-155.

Cunha, M., Xavier, A., \& Castilho, P. (2016). Understanding self-compassion in adolescents: Validation study of the Self-Compassion Scale. Personality and Individual Differences, 93, 56-62. https://doi.org/10.1016/j.paid.2015.09.023

Hombrados-Mendieta, M. I., Gomez-Jacinto, L., Dominguez-Fuentes, J. M., Garcia-Leiva, P., \& CastroTravé, M. (2012). Types of Social Support Provided By Parents, Teachers, and Classmates During Adolescence: Social Support Provided by Parents, Teachers, and Classmates. Journal of Community Psychology, 40(6), 645-664. https://doi.org/10.1002/jcop.20523

Hurlock, E. B. (2002). Psikologi Perkembangan. Jakarta: Erlangga.

Maheux, A., \& Price, M. (2016). The indirect effect of social support on post-trauma psychopathology via self-compassion. Personality and Individual Differences, 88, 102-107. https://doi.org/10.1016/j.paid.2015.08.051

Mulyana, H., \& Purnamasari, S. E. (2010). Hubungan Antara Harga Diri dengan Sikap terhadap Perilaku Seksual Pranikah pada Remaja dari Keluarga Broken Home. Psycho Idea, 41-53.

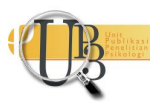


Nafisah, A., Hendriyani, R., \& Martiarini, N. (2018). Hubungan Antara Dukungan Keluarga Dengan Self Compassion Remaja Di Panti Asuhan. Intuisi Jurnal Psikologi Ilmiah, 10(2), 160-166. https://doi.org/2541-2965

Neff, K. (2003). Self-Compassion: An Alternative Conceptualization of a Healthy Attitude Toward Oneself. Self and Identity, 2(2), 85-101. https://doi.org/10.1080/15298860309032

Neff, K. D., \& McGehee, P. (2010). Self-compassion and Psychological Resilience Among Adolescents and Young Adults. Self and Identity, 9(3), 225-240. https://doi.org/10.1080/15298860902979307

Neff, K. D., \& Vonk, R. (2009). Self-Compassion Versus Global Self-Esteem: Two Different Ways of Relating to Oneself. Journal of Personality, 77(1), 23-50. https://doi.org/10.1111/j.14676494.2008.00537.x

Pálmarsdóttir, H. M. (2015). Parental Divorce, Family Conflict and Adolescent Depression and Anxiety. Department of Psychology School of Business, 1-21.

Salazar, L. R. (2015). Exploring the relationship between compassion, closeness, trust, and social support in same-sex friendships. The Journal of Happiness \& Well-Being, 3(1), 15-29.

Santrock, J. W. (2011). Life Span Development. Dallas: Mc. Graw-Hill.

Sarafino, E. P. (2011). Health Psychology: Biopsychosocial Interactions, Seventh Edition (7th ed.). USA: John Wiley \& Sons, Inc.

Strong, B., DeVault, C., \& Cohen, T. F. (2011). The marriage and family experience: Intimate relationships in a changing society (11th ed). Wadsworth, USA: Wadsworth Cengage Learning.

Tahirović, S., \& Demir, G. (2018). Influence of Parental Divorce on Anxiety Level of Adolescents. Contemporary Perspective on Child Psychology and Education, 85-101. https://doi.org/10.5772/intechopen.71287

Wilson, J. M., Weiss, A., \& Shook, N. J. (2019). Mindfulness, self-compassion, and savoring: Factors that explain the relation between perceived social support and well-being. Personality and Individual Differences, 152, 109568. https://doi.org/10.1016/j.paid.2019.109568

Wilson, K. (2017). Can Self-Compassion Reduce Depression and Anxiety in Adolescents? Intuition: The BYU Undergraduate Journal of Psychology, 12(2), 168-179.

Zimet, G. D., Dahlem, N. W., Zimet, S. G., \& Farley, G. K. (1998). The Multidimensional Scale of Perceived Social Support. 50(1), 30-41. https://doi.org/10.1207/s15327752jpa5201_2 